\title{
STUDY ON THE INFLUENCE OF ELECTRON BEAM ON THE PHYSICOCHEMICAL PROPERTIES OF POLYAMIDE 6
}

\author{
Rakhadilov B.K. ${ }^{1,2}$, Akatan K. ${ }^{1}$, Maulet M. ${ }^{1}$, Kabdrakhmanova S.K. ${ }^{1}$, Magazov N.M. ${ }^{{ }^{*}}$ \\ 1S.Amanzholov East Kazakhstan University, Ust-Kamenogorsk, Kazakhstan, magazovn@mail.ru \\ ${ }^{2}$ Plasma Science LLP, Ust-Kamenogorsk, Kazakhstan
}

\begin{abstract}
In this research work has been studied the effect of electron irradiation on the properties and structure of PA6 polyamide. The treatment was carried out with an industrial pulse accelerator in air with an irradiation dose in the range of 100-400 kGy. The processed polymer was also studied by Fourier-transform infrared spectroscopy, scanning electron microscopy, X-ray phase analysis and differential scanning calorimetry. According to the results of the study was known that electron beam treatment affects the crystal structure of polyamide-PA6, reducing its size. Also, it was found that the radiation dose of $200 k G y$ is optimal for preserving the crystal structure in comparison with 100, 300 and $400 k G y$.
\end{abstract}

Keywords: polyamide, electron beam, crystal structure, polymer, surface treatment.

\section{Introduction}

As a result of the development of science and technology, polymer materials have become increasingly important not only as electrical isolation in electrical installations but also as substitutes for traditional metal parts. This allows obtaining modified polymers that are economically effective and have the necessary physical and mechanical properties [1]. The method of processing polymer materials with an electron beam (EB) has been used for the last 50 years in production [2]. EB treatment has several advantages compared to the chemical modification method. In particular, the product does not contain any catalyst residues and by-products the process is repeated and simple, the exact amount of energy and temperature affected can be controlled [2-6].

Polyamide is one of the most widely used polymers in manufacturing due to its high strength, resistance to corrosion and aggressive environment and self-lubricating properties [7, 8]. But in the process of using as a movable particle under heavy loads at low temperatures, the friction coefficient of polyamide is large, a high degree of wear and under the influence of polar functional groups and hydrogen bonds in the molecule, absorbing a large amount of moisture mechanically changes to a more soft and plastic. This negatively affects the quality of the material and reduces the practical application [9-13]. At $22 \mathrm{kGy}$ using red phosphorus with a mass fraction of $12.5 \%$ as a binding agent was found the fire resistance of PA6-polyamide increases [14]. It is investigated that by processing polyamide-PA6 EB obtained without a binding agent, and it is possible to increase the thermal properties and reduce the water-absorbing properties [15]. Making the necessary changes in the properties of polymers due processing with high-energy electrons increases their practical significance. This proposed that studying polymer modification using EB and its changes leading to the polymer properties is relevant today.

It was found that the mechanism of processing the EB polymer is complex, and the possibilities of random processes are huge [16].In this study was studied the effect of electron beam treatment at various doses on the microstructure and morphology of the surface and the thermal properties of polyamide-PA6.

\section{Research materials and methods}

The study was used the disc-shaped sample TECAMID-6 (polyamide-6, Russia) (PA6) with a thickness of $0.1 \mathrm{~cm}$, diameter $2.5 \mathrm{~cm}$, carried out processing of industrial pulse accelerator (IL-10, Russia) in the air with an energy of $1.3 \mathrm{MeV}$, a current of $12 \mathrm{~mA}$, conveyor speed $3.5 \mathrm{~m} / \mathrm{min}$, the dose of $100,200,300,400 \mathrm{kGy}$. The chemical structure of the treated PA6 with EB was studied on a Fourier-IR spectrometer (Simex FTIR-801, Russia), the surface morphology on a scanning electron microscope (SEM) (JSM-6390LV), the thermal 
characteristic on a differential scanning calorimeter (Labsys Evo Setaram, France) in the temperature range of $20-300 \mathrm{C} 0$, the heating rate in the nitrogen atmosphere $+10 \mathrm{C} 0 / \mathrm{min}$.

\section{Results and discussion}

Figure 1 is shown the IR spectrum of PA6 untreated samples and treated samples under EB with irradiation doses of 100, 200, 300, and $400 \mathrm{kGy}$. Comparing the spectra, we see that all the absorption peaks of the PA6 samples treated by EB are similar to untreated PA6 sample's absorption peaks and do not have a new signal.The study was determined in the PA6 molecule at the peak of $976 \mathrm{~cm}-1$ of the $\mathrm{CO}-\mathrm{NH}$ group gave a $\beta$-crystal structure, $1118 \mathrm{~cm}-1 \mathrm{C}-\mathrm{C}, 1168 \mathrm{~cm}-1$ III-amide and the CO-NH group giving $\alpha$-crystal structure absorption values $928 \mathrm{~cm}-1-1260 \mathrm{~cm}-1$. These values similar to previous studies $[10,16]$.

The symmetric and asymmetric motion of the $1640 \mathrm{~cm}-1-1530 \mathrm{~cm}-1 \mathrm{~N}-\mathrm{H}$ group and $2860 \mathrm{~cm}-1-3080 \mathrm{~cm}-1$ $\mathrm{CH} 2$ absorption peaks are seen. And at a wavelength of $3300 \mathrm{~cm}-1$, there is a signal of a very weak variable hydrogen bond between $\mathrm{N}-\mathrm{H}$ and $\mathrm{C}=\mathrm{O}$ [17].The change in the absorption intensity of the critical peaks that provide information from changes in the chemical structure of PA6 after EB treatment is presented in Table 1.

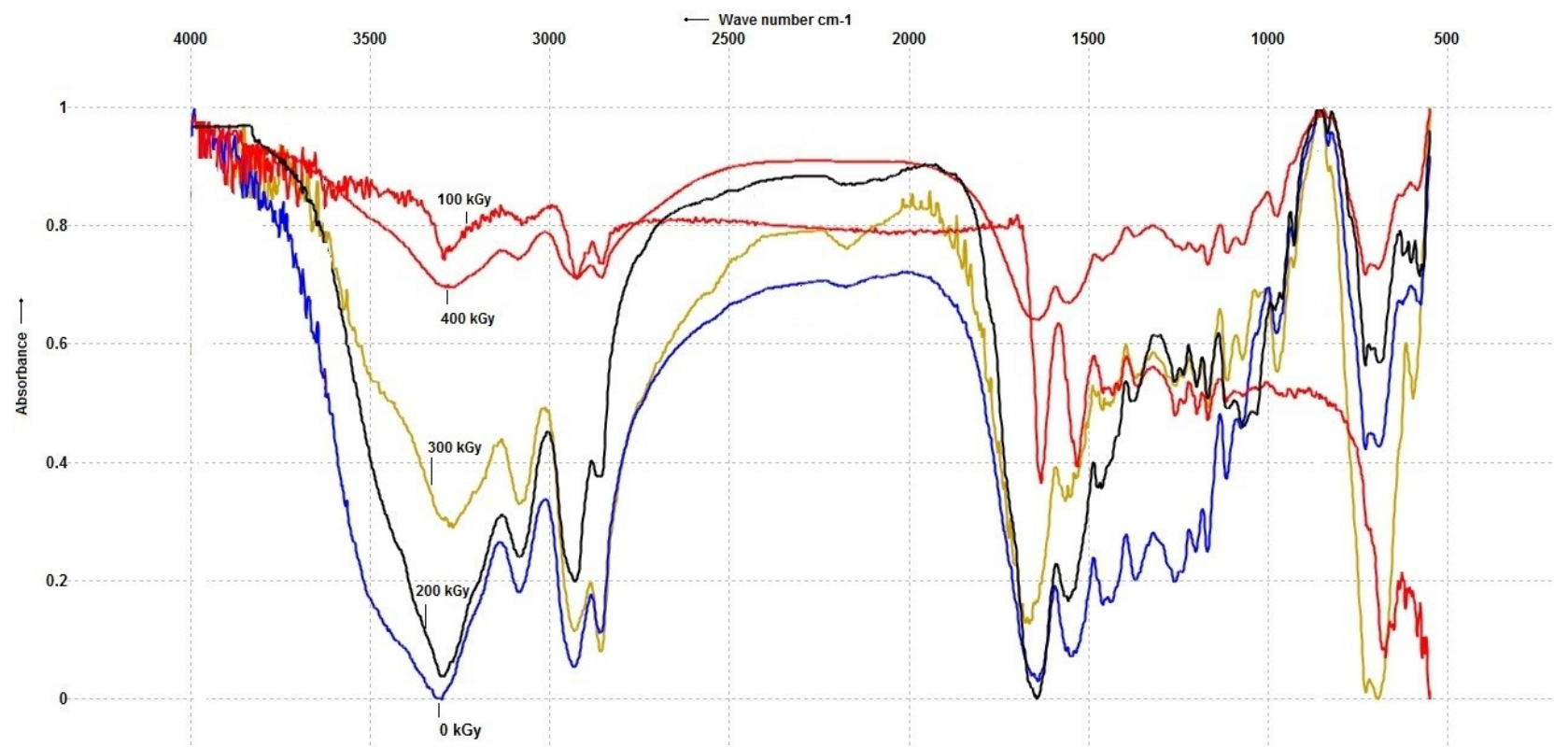

Fig.1. Comparative IR spectra of PA6 not treated with EB and treated at different EB doses. 0 to $400 \mathrm{kGy}$

Table 1. The relative intensity of PA6 in different IR absorption regions, varying within the radiation dose range from

\begin{tabular}{|c|c|c|c|}
\hline \multirow{2}{*}{$\begin{array}{c}\text { Electron beam dose, } \\
\mathrm{kGy}\end{array}$} & \multicolumn{3}{|c|}{ absorption intensity change, \% } \\
\cline { 2 - 4 } & $3300 \mathrm{~cm}-1$ & $1200 \mathrm{~cm}-1$ & $976 \mathrm{~cm}-1$ \\
\hline 0 & 0.997 & 0.752 & 0.548 \\
\hline 100 & 0.259 & 0.525 & 0.208 \\
\hline 200 & 0.944 & 0.505 & 0.565 \\
\hline 300 & 0.971 & 0.489 & 0.614 \\
\hline 400 & 0.303 & 0.265 & 0.277 \\
\hline
\end{tabular}

Based on the results in Table 1, we see that when the radiation dose was increased from $0 \mathrm{kGy}$ to $100 \mathrm{kGy}$, the absorption intensity of $3300 \mathrm{~cm}-1$ immediately decreased from $0.997 \%$ to $0.259 \%$. This indicates the break of the weak hydrogen bond between $\mathrm{N}-\mathrm{H}$ and $\mathrm{C}=\mathrm{O}$ after the $\mathrm{EB}$ irradiation [18]. We see that between $976 \mathrm{~cm}-1$ and 1200 cm- 1 the intensity of crystal building signals decreases from $0.548 \%$ to $0.277 \%$ and from $0.752 \%$ to $0.265 \%$, respectively, with an increase in the radiation dose. In the process of electron absorption, the polymer chain disintegrates, which is explained by the appearance of changes in the crystal lattice [19]. This phenomenon is clearly seen in Figure 3 as a result of the X-ray phase analysis.

Figure 2 shows a micrograph obtained from an electron scanning microscope (ESM) of changes in the polyamide surface morphology before treatment with PA6 EB and after treatment with different doses. The surface 
of the untreated PA6 sample with EB has a uniform spherulitic structure with minor scratches (Fig. 2a). With an increase in the EB dose from $0 \mathrm{kGy}$ to $400 \mathrm{kGy}$, a change in the surface topography of the sample and a violation of the spherulitic structure (2b-2e). This phenomenon is explained by the fact that under the action of the electron flow, the surface volume of polyamide increases, and the crystal properties decrease [19].

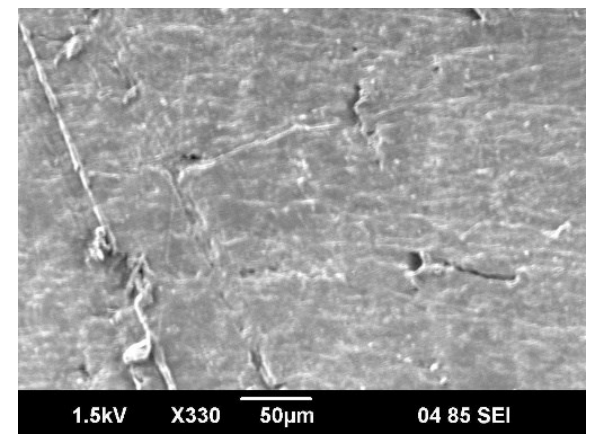

a)

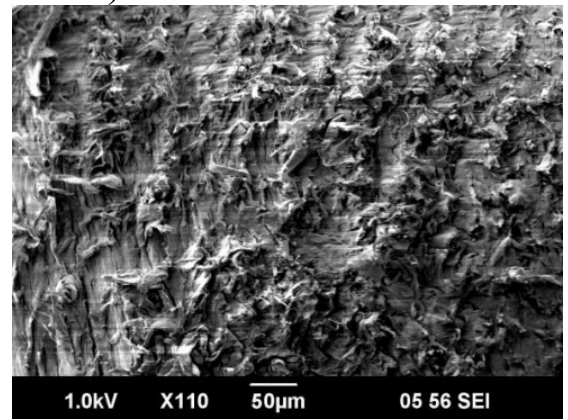

c)

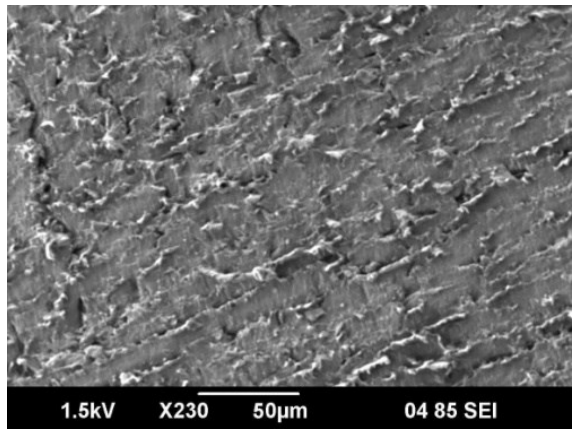

b)

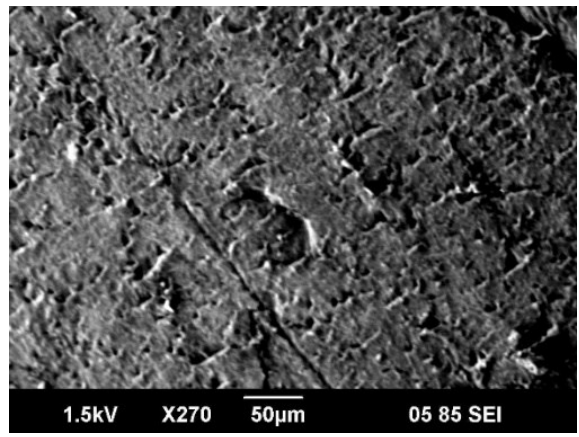

c)

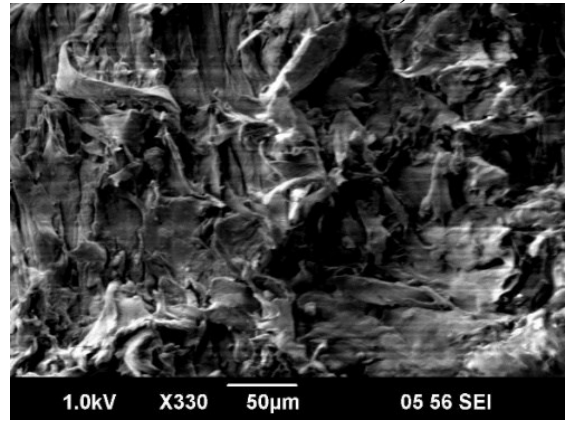

d)

Fig. 2. SEM micrograph of untreated with EB and treated with EB samples PA6 in different doses: a)-0 kGy; b)-100 kGy; c)-200 kGy; d)-300 kGy; e)-400 kGy

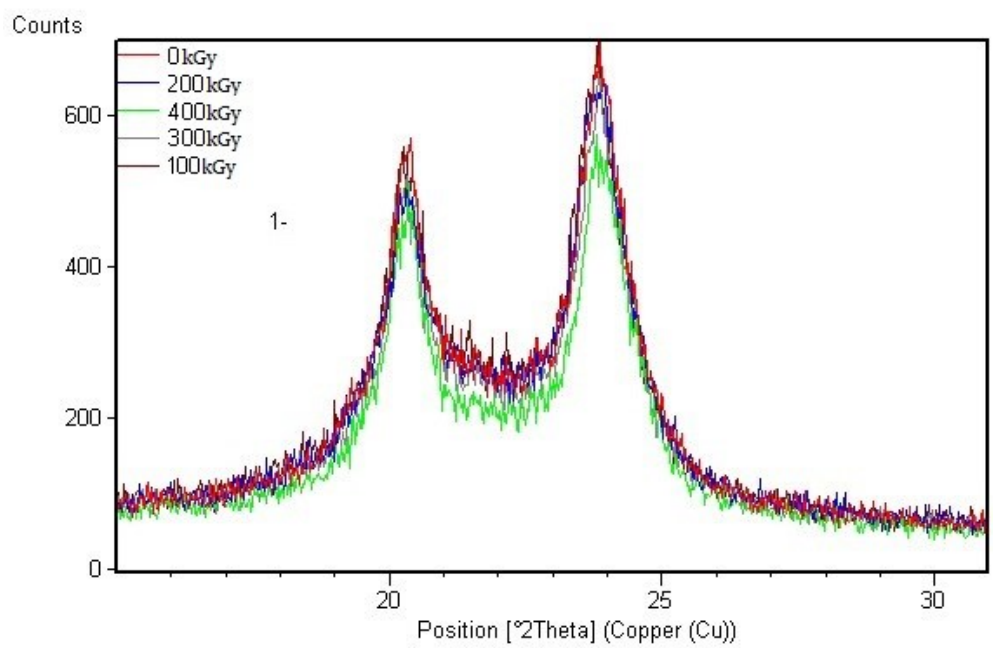

Fig.3. X-ray diffractogram PA6, not treated with EB and treated with EB in different doses

The X-ray phase analysis of PA6 sample not treated with EB and treated at different doses are shown in Figure 3.On the diffractogram $2 \theta 200$ and 240 from all the samples, we observe two intense peaks. This is the $\alpha$ crystalline phase of polyamide-PA6 [19]. The $\alpha$-crystal phase is visible at these angles is said in these studies [20, 21]. It can be seen that as the radiation dose increases from $0 \mathrm{kGy}$ to $400 \mathrm{kGy}$, the intensity of the peaks decreases compared to $0 \mathrm{kGy}$. This phenomenon is clearly seen in the thermal result of the DSC in Figure 4 and Table 2.At 0 $\mathrm{kGy}$, the melting point is $220^{\circ} \mathrm{C}$, the melting enthalpy is $57.33 \mathrm{~J} \cdot \mathrm{g}^{-1}$, and with an increase in the radiation dose to $400 \mathrm{kGy}$, the melting temperature and enthalpy respectively decreased to $215^{0} \mathrm{C}, 27.52 \mathrm{~J} \cdot \mathrm{g}^{-1}$. 


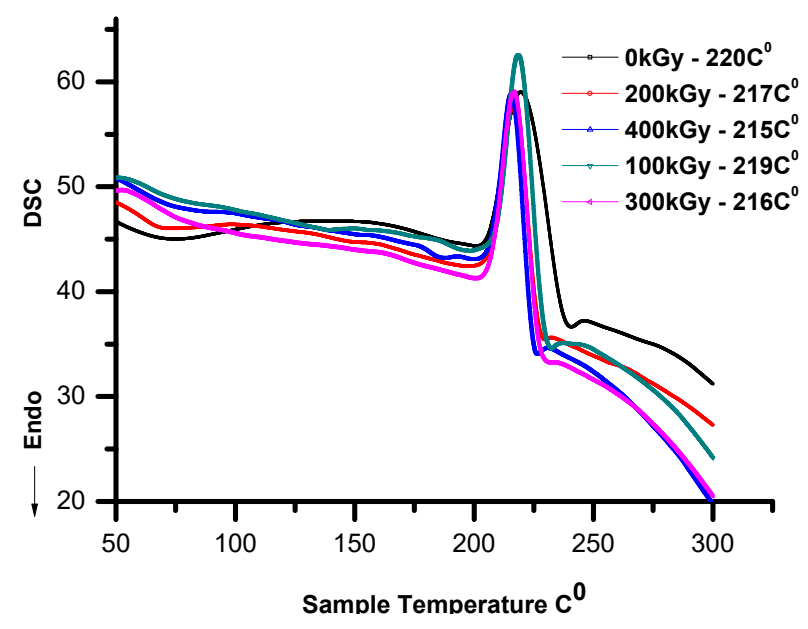

Fig.4. DSC thermogram samples -PA6, not treated with EB and treated with EB in different doses.

Table 2. DSC values of polyamide-PA6 untreated and treated with EB

\begin{tabular}{|c|c|c|}
\hline Radiationdose, $\mathrm{kGy}$ & Meltingpoint, $\mathrm{C}^{0}$ & Meltingenthalpy, $\mathrm{J}^{\mathrm{g}}{ }^{-1}$ \\
\hline 0 & 220 & 57.33 \\
\hline 100 & 219 & 57.07 \\
\hline 200 & 217 & 56.55 \\
\hline 300 & 216 & 27.65 \\
\hline 400 & 215 & 27.52 \\
\hline
\end{tabular}

During the process, the crystallinity decreases due to the inhibition of recombination and pyrolysis, the sewing of free radicals under the action of external electrons [22].

\section{Conclusion}

Based on the results of IR, SEM X-ray diffractometer and DSC was known that during the processing of $\mathrm{EB}$, the variable hydrogen bond in the polyamide-PA6 molecule disappears, crystallization decreases, but free radicals between the monomers bind under the action of an external electron flow. It was found that at a radiation dose of $200 \mathrm{kGy}$, the crystal structure is preserved in comparison with 100,300 and $400 \mathrm{kGy}$. It was revealed that the melting point of the PA6 polymer decreases from $220^{\circ} \mathrm{C}$ to $215^{\circ} \mathrm{C}$ after $\mathrm{EB}$. It was found that after EB there is a change in the topography of the sample surface and a violation of the spherulite structure. This phenomenon is explained by the fact that, under the action of an electron beam, the volume of the polyamide surface increases, and the properties of the crystal deteriorate.

\section{Acknowledgments}

The work was carried out within the framework of grant funding for scientific research on 2021 year by the Science Committee of the Ministry of Education and Science of the Republic of Kazakhstan (AP08957765).

\section{REFERENCES}

1 Raghu S., Archana K., Sharanappa C., et al. Electron beam and gamma ray irradiated polymer electrolyte films: Dielectric properties. Journal of Radiation Research and Applied Sciences, 2016, Vol. 9, pp. 117-124.

2 Leisen C., DrummerD. Infrared welding of cross-linkable polyamide 66. eXPRESS Polymer Letters,2016, Vol.10, No.10, pp. $849-859$.

3 Mondal M., Gohs U., Wagenknecht U., Heinrich G. Additive free thermoplastic vulcanizates based on natural rubber. Macromol. Chem. Phys.2013, Vol.143, pp. 360-366.

4 Boldt R., Gohs U., Wagenknecht U., Stamm M. Effect of electron-induced reactive processing on morphology and structural properties of high-density polyethylene. Polymer 95, 2016, Vol.95, pp. 1-8. 
5 Rakhadilov B.K., Sagdoldina Z.B., Ocheredko I.A., et al. Impact research of electron beam processing on the structure and properties of PA6 polyamide. Eurasian Physical Technical Journal. 2019, Vol.16, No.2, pp. 43-47.

6 Pramanik N.K., Haldar R.S., Bhardwaj Y.K. Radiation processing of Nylon 6 by e-beam for improved properties and performance. Radiat. Phys. Chem., 2009, Vol.78, pp.199-205.

7 Duxin Li, Ying Xie, Wen Juan Li, Yi Lan You, Xin Deng. Tribological and Mechanical Behaviors of Polyamide 6/Glass Fiber Composite Filled with Various Solid Lubricants. The Scientific World Journal, 2013, Vol.2013, pp. 1-9. doi: $10.1155 / 2013 / 320837$.

8 Ovsik M., Stanek M., Senkerik V. Influence of electron beam irradiated on the surface properties of polyamide measured by micro-indentation test. MATEC Web of Conferences 125, 2017, Vol.125, pp. $1-4$.

9 Meng H., Sui G. X., Xie G. Y., Yang R. Friction and wear behavior of carbon nanotubes reinforced polyamide 6 composites under dry sliding and water lubricated condition. Composites Science and Technology, 2009, Vol. 69, No.5, pp. 606-611.

10 Zhao R. G., Luo W. B., Xiao H. M., Wu G. Z. Water absorptivity and mechanical behaviors of PTFE/PA6 and PTFE/PA66 blends. Transactions of Nonferrous Metals Society of China, 2006, Vol. 16, Suppl. s2, pp. 498-503.

11 Chen Z., Li T., Yang Y., Liu X., Lv R. Mechanical and tribological properties of PA/PPS blends. Wear, 2004, Vol. 257, No. 7-8, pp. 696-707.

12 Burillo G., Adem E., Muñoz E., Vásquez M. Electron beam irradiated polyamide-6 at different temperatures. Radiat. Phys. Chem., 2013, Vol.84, pp.140-144.

13 Timus D.M., Cincu C., Bradley D.A., Craciun G., Mateescu E. Modification of some properties of polyamide-6 by electron beam induced grafting. Appl. Radiat. Isot., 2000, Vol.53, pp.937-944.

14 Pramanik N.K., Haldar R.S., Bhardwaj Y.K. Radiation processing of Nylon 6 by e-beam for improved properties and performance. Radiat. Phys. Chem., 2009, Vol.78, pp.199-205.

15 Dasgupta S., Hammond W.B., Goddard III W.A. Crystal structures and properties of nylon polymers from theory. Journal of American Chemical Society, 1996, Vol.118, No. 49, pp. 12291-12301.

16 Kim J.Y., Kim O.S., Kim S.H., Jeon H.Y. Effects of electron beam irradiation on poly(ethylene 2,6naphthalate)/poly(ethylene terephthalate) blends. Polym.Eng.Sci.2004, Vol.44, pp. 395-405.

17 Pramanik N.K., Sarwar Alam M., Khanda R.K. Electron Beam Irradiation of Nylon 66: Characterization by IR Spectroscopy and Viscosity Studies. International Journal of Innovative Research in Science. 2015, Vol. 4, Issue 1, pp. 18547-18555. doi: 10.15680/IJIRSET.2015.0401019.

18 Makuuchi K., Cheng S. Radiation Processing of Polymer Materials and Its Industrial Applications. New Jersey, 2012, $444 \mathrm{p}$.

19 Shifeng Zhu, Meiwu Shi, Meifang Zhu. Effects of Electron-Beam Irradiation Crosslinking on PA6 Fibers. Fibers and Polymers, 2013, Vol.14, No.4, pp. 525-529.

20 Sibilia J.P. A Guide to Material Characterization and Chemical Analysis. New York, 1996, 318 p.

21 Shailesh M.K., Kumar A. Radiation-induced grafting of vinylbenzyl trimethyl ammonium chloride onto nylon-6 fabric. Radiat. Phys. Chem., 2007, Vol.76, pp. $901-906$.

22 Nalwa H.S. Ferroelectric Polymers, New York, 1995, 895p. 